\title{
A Study of the Ossification of Anterior Sacroilac Ligament
}

\author{
Authors \\ Dr K. Parthiban ${ }^{*}$, Dr K.Vidulatha ${ }^{2}$ \\ ${ }^{1}$ Associate Professor, Institute of Anatomy, Madurai Medical College, Madurai \\ ${ }^{2}$ Assistant Professor, Institute of Anatomy, Madurai Medical College, Madurai
}

\begin{abstract}
Background: The sacroiliac joints are the largest axial joints in the body formed by the articulation of the innominate bones on the either side with the sacrum. These joints are huge and highly specialized as they play a pivotal role in the transmission of the entire weight of the upper part of the body to the lower limbs through the sacrum and the in nominal bones. The stability of the joints depends upon bony factors, bridges of depression in the auricular surfaces, the strong ligaments which connect the auricular surfaces, and the muscles which surround the joint. The ligaments which surround the joint may at times get ossified producing a variety of clinical conditions which may cause concern to physicians, neurologists and orthopaedician.

Keywords: Bony ankylosis, sacroiliac ligament innominate bone, ossification.
\end{abstract}

\section{Introduction}

The sacroiliac joints are deeply sealed true diarthrodial joints. The iliac part of the innominate bone has a ' $\mathrm{C}$ ' shaped depression called as the auricular surface of the ilium. Above the articular surface of the ilium. Above the auricular surface is an area with irregular elevation called as iliac tuberosity the interosseous surface of ilium.

The sacrum has a ' $L$ ' shaped elevated area called as auricular part of sacrum. Dorsal to the auricular area, the sacrum presents a concave depression called the interosseous surface of the sacrum.

The auricular surface of the sacrum and iliac bones are reciprocally in the anteroinferior part forming a synovial joint. The iliac tuberosity articulates with the dorsal depression in sacrum forming a posterosuperior syndesmosis. The sacral surface of the joint is covered with thick hyaline cartilage and the iliac surface is covered with thin fibrocartilage.

The joint has been variously classified as bicondylar type of synovial joint ${ }^{1}$ and fibrous joint $^{2}$ (Amphiarthrosis and Synarthrosis). Surface area of the joint cavity in adults is about $17.5 \mathrm{~cm}$. The joint space is usually 0.5 to $4 \mathrm{~mm}$.

These joints show age related changes in their characteristics. These joint surfaces are planas or flat during the early period of life but as the person starts walking the joint surfaces become irregular and show elevation and depression and slowly start acquire their adult characteristics (BROOKE 1924).

With advancing age, these joints show thickening of their capsules and synovial tissues. They also show extensive degenerative changes in their 
articulating cartilages. In some cases the joint spaces become obliterated, ligaments may be ossified, degenerative changes may set in or may end up in bony ankylosis.

These joints play a main role in the push-off phase of gait during which the joint becomes continent. These joints are capable of a very small amount of movement in the range of about 2-18 degrees.

The normal movements possible in the joint are

$>$ Anterior innominate tilt.

$>$ Posterior innominate tilt.

$>$ Antagonistic innominate tilt.

$>$ Nutation and counternutation.

During these movements there is 4 rotation and $1.6 \mathrm{~mm}$ of translation movement. These movements are more pronounced in women during pregnancy due to the effects of hormones like relaxin. The changes in the public symphysis along with the loosening of the ligaments which surround sacroiliac joints help in the process of delivery. The stability and strength of the joint in females are sacrificed in the greater range of movements (prooke 1924).

The joint is strengthened by means of both intrinsic and extrinsic ligaments. The extrinsic ligaments are sacrotuberous and sacrospinous ligaments. The intrinsic ligaments are anterior and posterior sacroiliac ligaments and interosseous sacroiliac ligament (Puhakka, melsen, jurik et al 2004).

The anterior sacroiliac ligament is thinner and weaker than the posterior and interosseous sacroiliac ligament is usually lookedas a moderate thickening of the anterior part of the fibrous joint capsule. It stretches from the preacricular sulcus of the ilium to the third sacral ligament. The ligament is better appreciated and developed near the posterior superior iliac spine and the arcuate line.

\section{Materials and Methods}

A study was conducted in 50 pelvis of unknown sex and age in Madurai medical college over a period of 1 year. During the study partial to computer ossification of the anterior sacroiliac ligament was observed in 5 pelvic bones. The length and site of ossification was noted. The presence of any other bony changes were noted. The results are summarized.

\section{Results \\ Specimen 1}

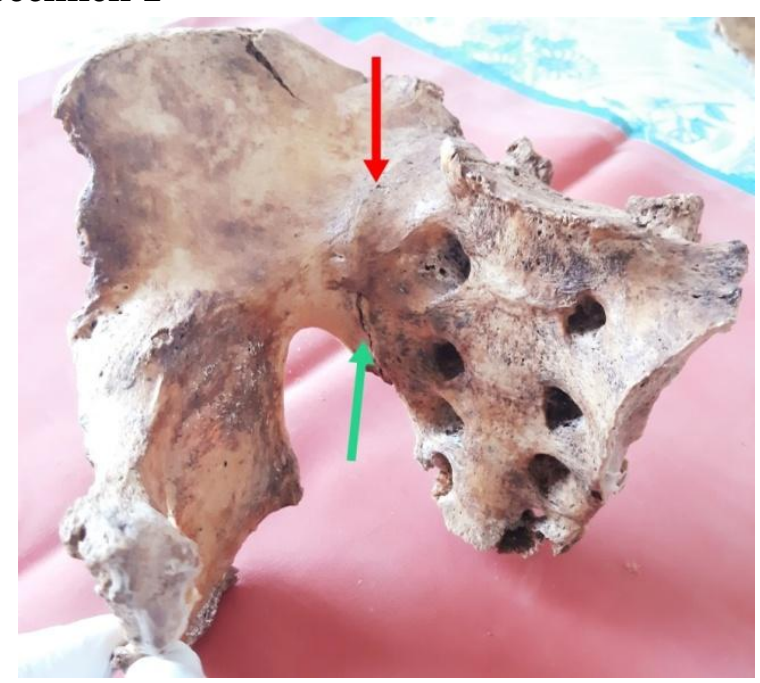

(Note: Red arrow-ossified, Green -Unossified) In specimen 1 the Right sided anterior sacroiliac ligament was ossified from the upper part till the end. The total length of ossification was $6 \mathrm{~cm}$. A small part of the posterior sacroiliac ligament was ossified in the lower part. The length of the ossification was $2 \mathrm{~cm}$. However the interosseous sacroiliac ligament was not ossified.

\section{Specimen 2}

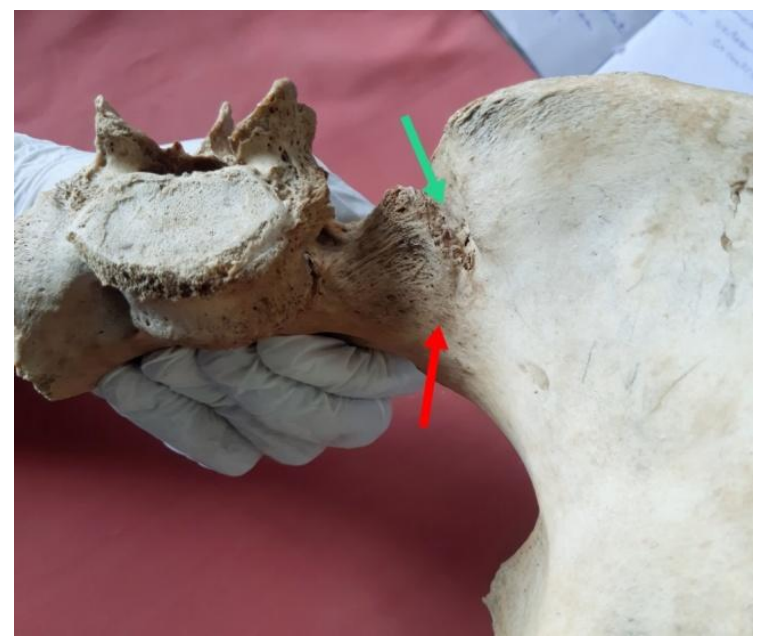

In specimen 2, the Right sided anterior sacroiliac ligament was ossified from the upper part till the middle. From the middle to the lower part it was not ossified. The length of ossification was $5 \mathrm{~cm}$. 
The posterior of interosseous sacroiliac ligaments were not ossified.

\section{Specimen 3}

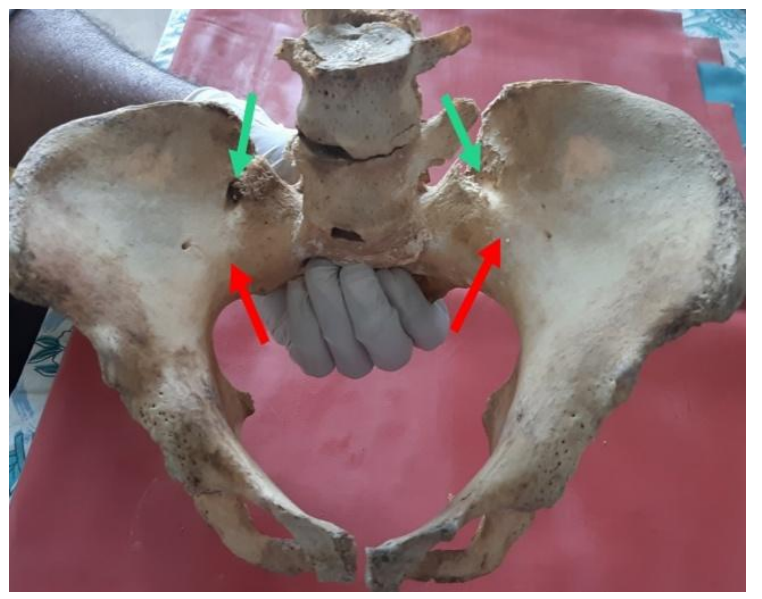

In specimen 3 the Left sided anterior sacroiliac ligament was ossified from the middle part till the end. The upper part of the ligament was not ossified. The length of ossification was $4 \mathrm{~cm}$. The posterior and interosseous sacroiliac ligaments were not ossified.

\section{Specimen 4 and 5}

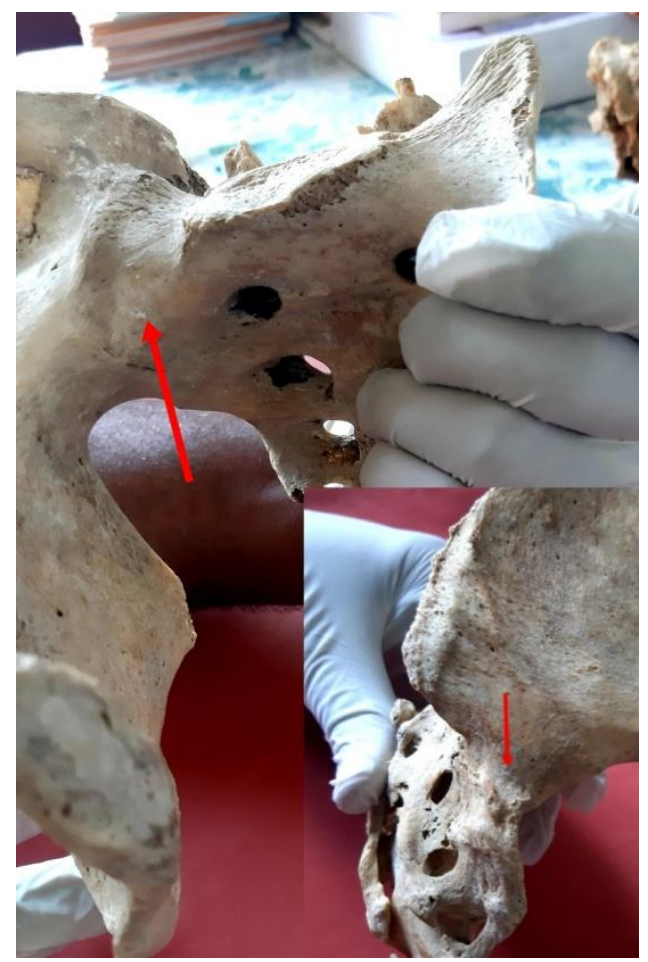

Both the anterior sacroiliac joints were ossified from the middle part till the end. The upper part of the sacroiliac joint were not ossified on both sides. The length of ossification was approximately about $5 \mathrm{~cm}$ on both sides. The posterior sacroiliac ligaments were not ossified. The L4 and L5 verteora were party fused and there was sacralisation of L5 vertebra.

\section{Discussion}

Studies on sacroiliac joint, its ligaments and the pathology related to the joints have been very limited. The inaccessibility of the joint and its inherent anatomical location might be considered as possible causes.

Mac Donald and T.E Hunt noted fusion of 2 sacroiliac joints in the age group of 60-69 yrs. They noted complete bony ankylosis in 2 specimens.

Incomplete ossification of anterior sacroiliac ligament on the left side was noted by R.Singh.

Sharmila and Sankar noted bilateral ankylosis of sacroiliac joint with the ossification of sacrospinous sacrotuberous and transverse ligament.

Sometimes, the ossified ligaments between ilium and sacrum can appear as digits or as ribs. In pelvis and abdomen anomalies of these kinds are called as pelvis (or) sacral digits or ribs.

\section{Conclusion}

The sacroiliac joint is usually considered as a common source of low back ache. The presentation may be either alone or in combination with other conditions like lateral recent syndrome facet syndrome herniated nucleus pulposes. In all these conditions the pain may be referred to the sacroiliac joint.

Another condition of concern is the arthropathy of the sacroiliac joint. It may cause chronic back ache. The ossification of the ligaments of the joint may compress upon the adjoining neurovascular structures and may be a source of low back ache. So a thorough knowledge of the sacroiliac joint is a must before treating conditions of low back ache.

\section{Reference}

1. Standring, S. Gray's Anatomy: anatomical basis of clinical practice. 39th ed. London: 
Elsevier Churchill Livingstone, 2005. p. 1428-1442.

2. Hollinshead $W H$. Functional Aanatomy of the Limbs and Back. Philadelphia, $P a$, USA: W.B. Saunders; 1969.

3. Sacroiliac Joint a review: Tilvawala K, Kothari K, Patel R. www.indian pain.org/article asp? Issn.0970-5333; year 2018; volume-32.

4. Collins D.H: The pathology of articular and spinal diseases. Edward Arnold \& Co., London,p.316,1949.

5. AVleemingM D SchuenkeA.The sacroiliac joint: an overview of its anatomy, function and potential clinical implications. J Anat. 2012 Dec; 221(6): 537-567. Published online 2012 Sep 19. doi: 10.1111/j.14697580.2012. 01564. PMCID: PMC 3512279 PMID: 22994881

6. SINGH, R Ossification of anterior sacroiliac ligament and its clinical significance Journal of morphological sciences 32(4):267-268.Jan 2015 DOI:10.4322/JMS 065213

7. SHARMILA, B. and SANKAR, KD. Bilateral ankylosis of sacroiliac joint with ossified sacrospinous, sacrotuberous and transverse acetabular ligaments. Int $\mathrm{J}$ of Anat Variations, 2011, vol. 4, p. 123-127.

8. BROOKE, R. The sacroiliac joint. Journal of Anatomy, 1924, vol. 58, n. Pt 4, p. 299305. PMid:17104023.

9. PUHAKKA, KB., MELSEN, F., JURIK, AG., BOEL, LW., VESTERBY, A. and EGUND, N. MR imaging of the normal sacroiliac joint with correlation to histology. Skeletal Radiology, 2004, vol. 33, n. $1, \quad$ p. 15-28. http://dx.doi.org/10.1007/s00256-0030691-4. PMid:14614576.

10. MacDonald GR, Hunt TE. Sacroiliac joints; observations on the gross and histological changes in the various age groups. Canadian Medical Association journal. 1952; 66(2):157-163. [PMC free article][PubMed]

11. MCGLONE, BS., HAMILTON, S. and FITZ GERALD, MJ. Pelvic digit: an uncommon developmental anomaly. European Radiology, 2000, vol. 10, n. 1, p. 89-91.

http://dx.doi.org/10.1007/s003300050010. PMid:10663721.

12. GOYEN et al, The pelvic digit: a rare development anomaly, a care report with CT correlation and review of the literature. ActaRadiologica (Stockholm, Sweden), 2000, vol. 41, n. 4, p. 317-319. http://dx.doi. org/10.1080/028418500127345569. PMid:10937749.

13. Takeshi Imamura et al, Characterization of Individuals with Sacroiliac Joint Bridging in a Skeletal Population: Analysis of Degenerative Changes in Spinal Vertebrae. BioMed Research International ,Volume 2014, Article ID 879645, 9 pages, http://dx.doi. org/10. 1155/2014/ 879645. 